\title{
Cognitive and spectral coherence of EEG alterations in resting state in children with chronic TBI
}

\author{
Marlene Galicia-Alvarado, ${ }^{1,4}$ Javier Alducin-Castillo, ${ }^{2}$ Maura Jazmín Ramírez-Flores, ${ }^{3}$ Ana Laura Sánchez Quezada, ${ }^{4}$ \\ Oscar Yáñez-Suárez, ${ }^{5}$ Blanca Flores-Ávalos ${ }^{4}$
}

Division of Biomedical Research, Instituto Nacional de Rehabilitación Luis Guillermo Ibarra Ibarra, Mexico City, Mexico.

2 Department of Electronics and Instrumentation, Universidad Autónoma Metropolitana-Azcapotzalco, Mexico City, Mexico.

${ }^{3}$ Laboratory of Neuropsychology and Cognition, School of Psychology, UNAM, Mexico City, Mexico.

${ }^{4}$ Department of Electrodiagnostic, Instituto Nacional de Rehabilitación Luis Guillermo Ibarra Ibarra, Mexico City, Mexico.

${ }^{5}$ Laboratory of Neuroimaging, Universidad Autónoma Metropolitana-tztapalapa, Mexico City, Mexico.

\section{Correspondence:}

Marlene Alejandra Galicia Alvarado Calz. México Xochimilco 289, Col. Arenal de Guadalupe, C.P.14389, Ciudad de México, México.

Phone: +52 55 5999-1000 ext. 13266

Email: magalicia@inr.gob.mx

Received: 17 May 2018

Accepted: 23 April 2019

Citation:

Galicia-Alvarado, M., Alducin-Castillo, J., Ramírez-Flores, M. J., Sánchez Quezada, A., L., YáñezSuárez, O., Flores-Ávalos, B. (2019). Cognitive and spectral coherence of EEG alterations in resting state in children with chronic TBI. Salud Mental, 42(2), 91-100.

DOI: $10.17711 /$ SM. $0185-3325.2019 .012$

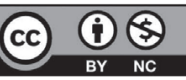

\begin{abstract}
Introduction. TBI is associated with alterations in cortico-subcortical connectivity. However, little attention has been paid to its clinical characteristics and functional connectivity in pediatric patients with chronic TBI. Objective. To evaluate the cognitive performance and spectral coherence of a group of children with TBI in non-acute phase. Method. Cross-sectional study of 15 children with chronic TBI and 17 healthy children. The Neuropsychological Assessment of Children (Evaluación Neuropsicológica Infantil, ENI) was used and the resting activity of the EEG with eyes-closed was recorded. Offline, two-second epochs of the EEG of each participant were chosen and the spectral coherence was estimated in a range of $1.6 \mathrm{to} 30 \mathrm{~Hz}$. The cognitive performance between groups was compared with T-test/Mann-Whitney $U$ Test and MANOVA for the coherence values. Results. The TBI group showed a lower performance $(p \leq 0.05)$ in metalinguistic, visuospatial skills, attention, memory, non-verbal flexibility, planning, and organization. Differences $(p \leq 0.000)$ were found both inter and intrahemispherically in the spectral coherence between the groups, particularly on $\mathrm{F} 1-\mathrm{F} 3(95 \% \mathrm{Cl}$ : $0.543-0.557)$ over the whole frequency range and $\mathrm{F} 3-\mathrm{C} 3(95 \% \mathrm{Cl}: 0.503-0.515)$ in delta, theta, alpha2, and beta frequencies. Discussion and conclusión. Our findings suggest alterations of hypo and hyper functional connectivity, particularly on the frontal and parietal lobes of both hemispheres, even after several years of a TBI. It is possible that a subtle difference in the degree of connectivity is crucial in the genesis or successful development of attentional, mnesic, executive, and visuospatial processes.
\end{abstract}

Keywords: EEG, cognition, child, traumatic brain injury.

\section{RESUMEN}

Introducción. El TCE se asocia con alteraciones en la conectividad cortico-subcortical. Sin embargo, se ha prestado poca atención a las características clínicas y de conectividad funcional en pacientes pediátricos con TCE crónico. Objetivo. Evaluar el desempeño cognitivo y la coherencia espectral de un grupo de niños con TCE en fase no aguda. Método. Estudio transversal de 15 niños con TCE y 17 niños controles. Se empleó la Evaluación Neuropsicológica Infantil (ENI) y se registró la actividad en reposo del EEG con ojos cerrados. Fuera de línea, se eligieron épocas de $2 \mathrm{~s}$ del trazo de cada participante y se estimó la coherencia espectral en un rango de 1.6 a $30 \mathrm{~Hz}$. Se comparó el rendimiento cognitivo entre los grupos con la prueba T/U-Mann de Whitney y MANOVA para los valores de coherencia. Resultados. El grupo con TCE mostró un menor rendimiento $(p \leq 0.05)$ en habilidades metalingüísticas, visuoespaciales, atención, memoria, flexibilidad no verbal, planeación y organización. Se encontraron diferencias $(p \leq 0.000)$ en la coherencia espectral tanto inter como intrahemisférica entre los grupos. Particularmente, en F1-F3 (95\%IC: $0.543-0.557)$ en todo el rango de frecuencias y F3-C3 (95\%IC: 0.503 - 0.515) en delta, theta, alfa2 y beta. Discusión y conclusión. Los resultados sugieren que distintas redes en estado de reposo muestran alteraciones de hipo e hiperconectividad funcional aun después de varios años de un TCE. Es probable que una sutil diferencia en el grado de conectividad sea determinante en la génesis o el desarrollo exitoso de procesos atencionales, mnésicos, ejecutivos y visoespaciales.

Palabras clave: EEG, cognición, niños, traumatismo craneoencefálico. 


\section{INTRODUCTION}

Traumatic Brain Injury (TBI) refers to any physical injury and functional deterioration on the head, which results from the abrupt exchange of mechanical energy exerted directly and indirectly on the brain (Stocchetti, Conte, Ghisoni, Canavesi, \& Zanaboni, 2010). The lesions can lead to fracture of the skull, contusion, epidural and subdural hematoma, subarachnoid hemorrhage, ischemia, edema, diffuse axonal damage, synaptic dysfunction, and gliosis (Blennow, Hardy, \& Zetterberg, 2012; Ramlackhansingh et al., 2011). TBI is one of the main causes of mortality and disability in children worldwide (Adelson et al., 2003; Pan et al., 2006). In Mexico, it is estimated that it is the leading cause of death among children under 15 years old and of physical and cognitive disability (Garduño-Hernández, 2008; INEGI, 2015).

TBI has been shown to be associated with alterations in the structural and functional connectivity of the brain (Hannawi \& Stevens, 2016) due to the damage of tracts and fibers of white matter (Kirkwood et al., 2008), as well as to the imbalance and inefficiency of various neural networks that lead to specific cognitive disorders (Ewing-Cobbs et al., 2004). Despite the fact that pediatric TBI is generally associated with global cognitive deficiencies, after a TBI children frequently present perceptual, mnesic (Taylor et al., 2002; Yeates, Blumenstein, Patterson, \& Delis, 1995), attentional, executive function (Anderson \& Catroppa, 2005; Levin \& Hanten, 2005), linguistic (Ewing-Cobbs \& Barnes, 2002), and psychomotor speed impairment.

The development and integrity of these superior functions are known to depend on the coordinated activation of different neuronal sets, that is, the functional integration between neural populations (Catani \& Ffytche, 2005; Stam \& van Straaten, 2012). The study of integration and functional connectivity has traditionally employed the spectral coherence of the electroencephalographic signal (EEG) as a possible indicator of the degree of coupling or synchronization between brain regions, spatially different as a function of frequency (Paus, 2007; Sakkalis, 2011). From this perspective, a high coherence between two EEG signals suggests a high functional integration between neuronal populations, either directly through the cortico-cortical fibers or indirectly through cortico-subcortical networks (Gmehlin et al., 2011; Murias, Swanson, \& Srinivasan, 2007).

In the last decade, the study of functional connectivity in resting state has been used in different areas of experimental and clinical neurosciences, including development studies. Several lines of research converge on the fact that spontaneous or resting brain activity is organized topographically in various functional networks (Yeo et al., 2011), which increases their strength of functional connectivity through age and development of cognitive functions (Khundrakpam, Lewis, Zhao, Chouinard-Decorte, \& Evans, 2016). In fact, that cognitive change from lifespan developmental relates to the microstructural integrity of the underlying white matter fiber tract of some resting state networks and their functional connectivity.

The great advantage of resting state with eyes closed is that it can be investigated if the participant is not involved in a task, which is really useful in groups with limited cooperative capacity such as children or patients with developmental delay. In addition, patients and controls can be compared to the assumption that groups use similar strategies to solve a task (Bathelt, O'Reilly, Clayden, Cross, \& de Haan, 2013). Furthermore, the closed eyes condition is more stable over sessions when quantifying EEG parameters than the eyes open condition (Corsi-Cabrera, Galindo-Vilchis, del-Río-Portilla, Arce, \& Ramos-Loyo, 2007). Another advantage is that attrition rates are relatively low and the children exhibit less gross motor movements, eye blinks, or lateral eye movement which contaminate the EEG recording in such a way that it is possible to collect a sufficient number of artifact-free epochs for data analysis (Bell \& Cuevas, 2012).

In healthy subjects, it has been proposed that the degree of interregional functional connectivity is different depending on age (Barry et al., 2004), distance, and frequency band (Catani et al., 2005; Thatcher, Krause, \& Hrybyk, 1986; von Stein \& Sarnthein, 2000). According to some authors, long distance connections are mainly maintained in the synchronization in low frequency bands (delta and theta), while local or short distance connections depend on synchronization in the beta and gamma frequencies (Thatcher, North, \& Biver, 2008; von Stein, Rappelsberger, Sarnthein, \& Petsche, 1999). Therefore, the coherence analysis of the EEG represents a pragmatic tool to assess the impact of TBI on neuronal functional connectivity and integration.

In patients with chronic TBI, a large number of studies with functional Magnetic Resonance have identified a significant decrease in functional connectivity within the nodes of the front-parietal, dorsal network, and the thalamic, motor, salience, and executive control default neural network, as well as alterations in their interaction (Bonelle et al., 2011; Han, Chapman, \& Krawczyk, 2016; Hayes, Bigler, \& Verfaellie, 2016; Sharp, 2011). However, there is also evidence that TBI is associated with an increase in the connection between some nodes of these networks (Caeyenberghs et al., 2012; Hillary et al., 2011; Palacios et al., 2013; Sours, Zhuo, Roys, Shanmuganathan, \& Gullapalli, 2015).

Despite the importance of pediatric TBI in terms of public health, there are few studies that examine post-injury cognitive development in young children, and even less to investigate the characteristics of functional connectivity of chronic traumatic brain injury through the EEG. Although in the last decade resting state EEG connectivity and functional brain network studies have gained considerable interest, there is still little data about the typical/atypical maturation of functional connectivity and its role in cognitive 
developmental. Most of the findings on TBI come from adult population, with neuroimaging techniques and in the sub-acute phase.

Children who sustain TBI in early childhood also show little evidence for recovery of cognitive functions compared with children injured at later ages, and findings suggest that severe TBI in early childhood may be particularly at risk for residual cognitive impairments and behavioral deficits during adolescence and youth (Muscara, Catroppa, \& Anderson, 2008; Nadebaum, Anderson, \& Catroppa, 2007). The disturbed development of neural networks and skills in the process of consolidation after a TBI during childhood can permanently affect academic, social, and affective performance (Anderson, Catroppa, Morse, Haritou, \& Rosenfeld, 2005a; Taylor \& Alden, 1997). Therefore, the objective of this study was to assess the cognitive abilities and functional cortical connectivity of a group of children with TBI in non-acute phase.

\section{METHOD AND MATERIALS}

\section{Design}

Quantitative, comparative descriptive, cross-sectional study.

\section{Participants}

An intentional, non-probabilistic sample of 15 children (3 girls) with low to severe TBI background $(8.3 \pm 1.5$ years of age; evolution time: $31.1 \pm 26.7$ months) was selected from the Instituto Nacional de Rehabilitación Luis Guillermo Ibarra Ibarra, the Instituto Nacional de Pediatría (INP) and health centers of Mexico City. Seventeen children from elementary schools as control group ( 9 girls; $8.4 \pm 1.5$ years of age) were included in the study. The recruitment period was from September 2014 to December 2015.

In an interview with the parents, the development and learning history of the participants was collected through the Questionnaire for Parents and the Clinical History of Neuropsychological Assessment of Children (ENI) (Matute, Rosselli, Ardila, \& Ostrosky-Solís, 2007). Cases with the following conditions were excluded: 1 . neurological disorders, delay speech acquisition and/ or psychomotor development (before the injury for the group with TBI) and 2. signs of depression, anxiety, defiant opposition, or other neurodevelopmental disorder according to the DSM-V. None of the children was under medication during the course of the study.

\section{Procedures}

Parents and participants were explained the procedures and assessments to be carried out. The parents and guardians read and signed the informed consent and subsequently fulfilled questionnaires to measure their socioeconomic status with the AMAI Rule 8x7 (AMAI, 2013).

\section{Cognitive assessment}

In a second session, the cognitive performance of the participants was measured with the Neuropsychological Assessment of Children (ENI) in the following domains: attention, constructional abilities, memory, perception, language, visuospatial abilities, abstraction, and executive function. The ENI has been widely used in Mexico and the rest of Latin America and provides information on neuropsychological characteristics of children and teenagers 5-16 years old. In order to offer the normative data of this instrument, a series of reliability and validity procedures were carried out, such as test-retest reliability, reliability among qualifiers, correlations with the WISC, and internal validity of its tasks (Matute et al., 2007).

The same personnel, in the same schedule, made the assessment in all cases in a cubicle with adequate lighting and ventilation.

\section{EEG recording}

In a third session, the spontaneous activity at rest of the EEG was recorded with eyes closed, placing 16 electrodes on the scalp, utilizing the 10-20 International System of electrode placement and the impedances were kept below $5 \mathrm{k} \Omega$; for the purposes of this work, the findings of the first five minutes are described. Data were collected and recorded using a Nicolet ${ }^{\circledR}$ amplifier, 32-channel NicONE model, with a sample frequency of $256 \mathrm{~Hz}, 1.6-70 \mathrm{~Hz}$ bandpass and digitized at 16 bits. Additionally, electrodes were placed on the palpebral edge of both eyes to record eye movements, and on the masseter muscle to identify mandibular artifacts. The earth and reference are placed on the central line of the forehead.

\section{EEG processing}

After an offline visual inspection, epochs with evidence of muscle artifact were, where possible, rejected. 30 to 502 -second epochs of each participant were selected. All raw data were imported, pruned, notch filtered at $60 \mathrm{~Hz}$ into Octave ${ }^{\circledR}$ software. To minimize the influence of volume conduction on nearby electrodes, as well as the electrical activity typical of the assembly reference, the reference change technique known as CAR (Common Average Reference) was used (Alhaddad, 2012; Nunez et al.,1997). The referenced EEG signal was conditioned with a seventh order elliptical digital filter in the 1.6 to $40 \mathrm{~Hz}$ bandpass. The filter was applied to all channels in a non-zero phase causal manner. Eyes and muscle artifacts still on the EEG were removed using Independent Component Analysis (ICA) to identify sources of noise. The normality of the different components was contrasted by means of the statistical W of Shapiro-Wilk, which were highly non-normal. In this way, the EEG epochs were 
reconstructed with a selection of awake task-free data, with an average of one minute and a half for each subject. No group differences was observed in their number and length of the EEG epochs $(t=-1.92, p=0.06)$.

\section{Connectivity measure}

To estimate the connections between the two electrode signals, we used the spectral coherence function defined as:

$$
Y_{x y}(w)=\frac{\left|S_{x y}(w)\right|^{2}}{S_{x x}(w) S_{y y}(w)}
$$

where $S_{\mathrm{xx}}(W)$ and $S_{\mathrm{yy}}(W)$ are the spectral densities of the auto spectra of the time series $x$ and $y$ of two EEG electrodes; $S_{\mathrm{xy}}(W)$ is the density of the crossed spectrum and $w$ is the discrete frequency.

The method described by Welch (1967) was used to calculate the densities of the power spectra. Coherence estimates were obtained on 120 pairs of electrodes for the following frequencies $(\mathrm{Hz})$ : delta (1.6-4.0), theta (4.0- 8.0), alpha $_{1}(8.5-10.5)$, alpha 2 (11.0-13.0), and beta (13.5 -30).

\section{Statistical analysis}

Central tendency statistics were used to describe the sociodemographic data. Subsequently, a Student $t / \mathrm{U}-$ Mann Whitney test was applied to compare cognitive abilities between the groups. Finally, to account for differences in the coherence values of the electrode pairs, a MANOVA was used. The analysis was carried out through the SPSS program, version 19 (SPSS Inc., Chicago, IL).

\section{Ethical considerations}

Subject recruitment, data collection, and analyses were conducted with informed and assent consent for the participation of children in the study by the parents. The Instituto Nacional de Rehabilitación Luis Guillermo Ibarra Ibarra (INRLGII) Ethics and Research Committees in Mexico City approved the protocol (No. 66/14) in accordance with the criteria of the Declaration of Helsinki.

\section{RESULTS}

\section{Demographic data}

A total of 21 patients with chronic TBI and 23 healthy children were recruited in Mexico City, of whom five were excluded due to the presence of neurological antecedents and seven more children were eliminated due to not concluding the neuropsychological assessment and/or because they presented excess of movement in the EEG. Finally, 15 children (three girls) with a history of mild to severe TBI $(8.3 \pm 1.5$ years old, evolution time: $31.1 \pm$ 26.7 months) and 17 healthy children (9 girls, $8.4 \pm 1.5$ years old) were included in the study. Using Fisher's exact test group, differences were found in the groups in regard to socioeconomic level (Fisher $=9.5, p=.02$ ). This difference was controlled in all subsequent analyses through an analysis of covariance. No group differences were found

Table 1

Differences on Neuropsychological Assessment of Children (ENI)

\begin{tabular}{|c|c|c|c|c|c|c|}
\hline \multirow{2}{*}{\multicolumn{2}{|c|}{ Domain, Subcategory and task }} & & \multicolumn{2}{|c|}{ Control } & \multicolumn{2}{|c|}{ TCE } \\
\hline & & & M & $(S D)$ & M & $(S D)$ \\
\hline \multirow[t]{2}{*}{ Memory encoding } & Verbal & List of words ${ }^{a, *}$ & 11.0 & $(2.4)$ & 8.2 & $(2.7)$ \\
\hline & Visual & List of figures $\mathrm{a}^{\mathrm{a}, *}$ & 10.7 & $(1.7)$ & 8.6 & $(2.5)$ \\
\hline \multirow[t]{5}{*}{ Recovery } & Verbal & Spontaneous list of words & 10.6 & (2.3) & 9.0 & $(2.0)$ \\
\hline & & Keys word list $\mathrm{t}^{\mathrm{b}, *}$ & 12.5 & $(8.4)$ & 8.2 & $(2.6)$ \\
\hline & & Story ${ }^{\mathrm{b}, * *}$ & 10.5 & $(3.0)$ & 7.6 & (3.3) \\
\hline & Visual & Spontaneous list of figures ${ }^{a, *}$ & 11.4 & $(2.5)$ & 8.2 & $(2.0)$ \\
\hline & & Keys list of figures ${ }^{b, * *}$ & 11.2 & $(2.4)$ & 8.5 & $(1.9)$ \\
\hline Language repetition & & Sentences ${ }^{a, *}$ & 10.7 & $(2.4)$ & 7.6 & $(2.8)$ \\
\hline \multirow[t]{3}{*}{ Metalanguage } & & Phonemic synthesis ${ }^{b, * *}$ & 12.5 & (2.9) & 9.7 & $(2.6)$ \\
\hline & & Spelling ${ }^{\mathrm{b}, * *}$ & 12.5 & $(1.8)$ & 10.0 & $(3.2)$ \\
\hline & & Word count & 10.8 & $(3.6)$ & 7.9 & $(3.0)$ \\
\hline Spatial abilities & & Drawings from different angles ${ }^{\mathrm{b}, *}$ & 9.8 & $(1.5)$ & 7.1 & $(3.0)$ \\
\hline Atention visual & & Cancellation of letters & 10.5 & $(1.9)$ & 8.6 & $(3.0)$ \\
\hline Conceptual abilities & & Similarities ${ }^{a, *}$ & 14.0 & $(2.4)$ & 10.0 & $(3.1)$ \\
\hline Executive functions & & Semantic ${ }^{a, \star *}$ & 8.2 & (2.5) & 6.2 & $(1.6)$ \\
\hline Graphic fluency & & Nonsemantic $c^{a, *}$ & 9.9 & $(1.9)$ & 7.5 & $(2.2)$ \\
\hline Planning and organizing & & Number of movements $\mathrm{s}^{\mathrm{b}, * *}$ & 10.6 & $(3.0)$ & 5.0 & (3.9) \\
\hline
\end{tabular}

Notes: a t-test; ${ }^{\circ} /$ U-Mann Whitney test; ${ }^{*} p \leq .01 ;{ }^{* *} p \leq .05$.

Extremely low: 1-4, Low: 5-6, Low Average: 7, Average: 8-13, Hight average: 14-19. 
regarding age $(t=0.26, p=.79)$ and scholarship $(t=0.29$, $p=.77)$ of the participants.

The main mechanism of injury of the group with TBI was by fall ( $80 \%)$, followed by accidents $(20 \%) ; 67 \%$ of these cases were closed TBI and the degree of severity of the event was severe in $40 \%$, moderate in $33 \%$, and mild in $27 \%$ of cases.

\section{Cognition (ENI)}

In all the areas and subtests carried out, the control group was found in the average scalar range ( 8 to 13 ). The performance in visuospatial abilities of the TBI group was lower $(p \leq .05)$, particularly in the mental management of three-dimensional models (drawings from different angles). Similarly, the performance in conceptual skills of categorical abstraction (similarities) was lower (Table 1).

The group with TBI showed a lower performance in skills that involve selective visual attention (cancellation of letters), as well as in processes of encoding and retrieval of verbal and visual memory systems. In the same way, children with TBI showed a lower capacity to recover contextual information from a large volume of information. Regarding language, the group with TBI showed a lower capacity in metalinguistic skills (phonemic synthesis, spelling, and word counting), as well as in repeating and elaborating sentences of increasing complexity and volume. Finally, in executive functions, significant differences were found in planning and organization skills; children with TBI required a greater number of movements to sequentially anticipate actions for the construction of a presented model. In tasks of semantic and non-semantic graphic fluency, the group with TBI also showed a lower performance with respect to their peers (Table 1).

\section{Connectivity (Coherence)}

Figure 1 shows the pairs of electrodes with significant differences $(p \leq .05)$ in the values of spectral coherence between the groups. The effect of the interaction between the group (TBI, Control) and frequency band (delta, theta, al$\mathrm{pha}_{1}$, alpha $\mathrm{a}_{2}$, and beta) was statistically significant $(\mathrm{F}=2.21$, $p \leq .001)$. In general, children with TBI showed lower values of coherence in each one of the analyzed frequency bands. Sixty-seven percent of the connections in F3, F4, P3, P4, and T6 had a lower connectivity with the rest of the cortical regions in comparison to the control group. Similarly, $80 \%$ of the connections on the right occipital region $(\mathrm{O} 2)$ were lower. However, the most pronounced difference in the five frequency bands was between F1-F3 $(M=0.550, S D=0.194,95 \%$ CI: $0.543-0.557)$ with respect to the control group (F1-F3: $M=0.635, S D=0.185,95 \%$ CI: $0.628-0.640$ ) (Figure 1 and Figure 2A).

On the other hand, a consistent increase in coherence was observed (Figure 1, dotted lines) between F3-C3 ( $M=0.509$, $S D=0.184,95 \%$ CI: $0.503-0.515)$ in the delta, theta, alpha 2 ,
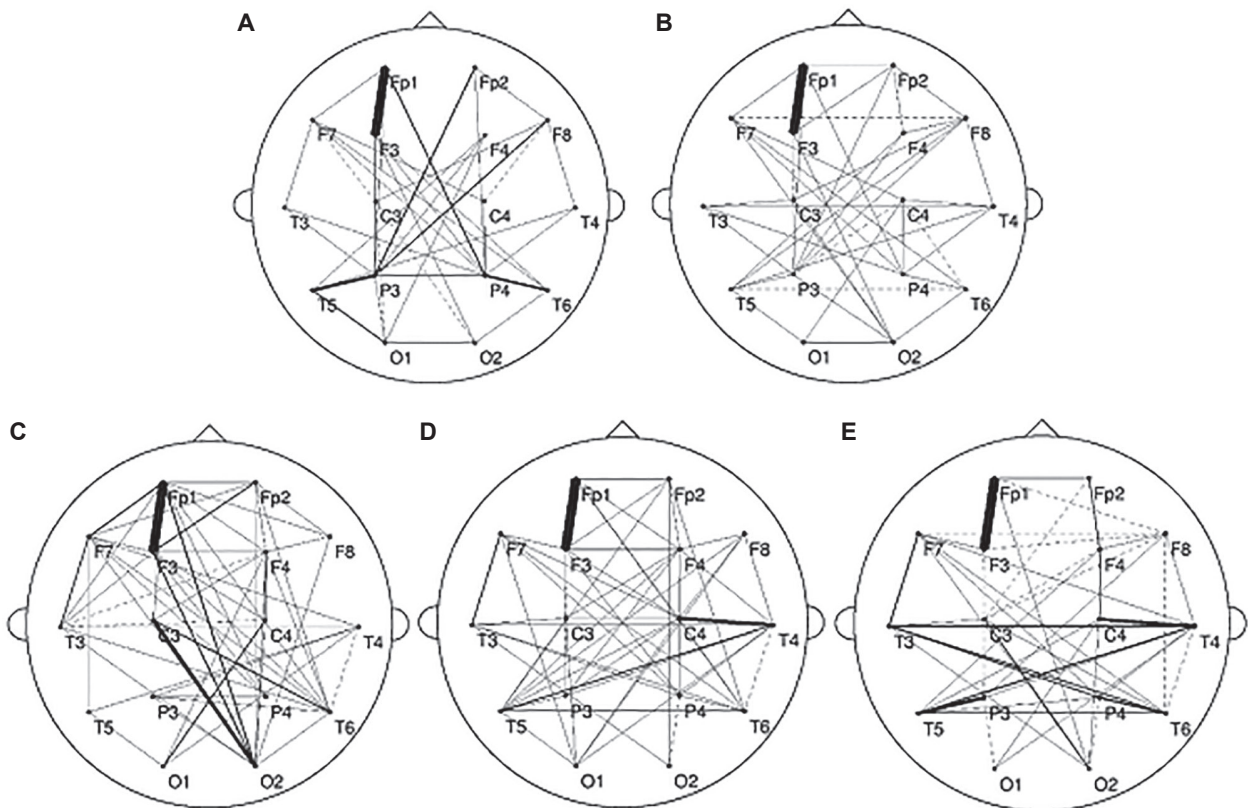

Figure 1. Topography of spectral coherence values with significant differences in children with TBI. The electrodes with less coherence are shown in solid line or with greater coherence in dotted line with respect to the control group with $p \leq .05$ in A) delta (0.5-4.0), B) theta (4.0- 8.0), C) alpha $(8.5-10.5)$, D) alpha $_{2}(11.0-13.0)$ and E) beta $(13.5-30 \mathrm{~Hz})$. The greater the thickness of the line, the larger is the difference found, the range of minimum variation was 0.01 and maximum of 0.11 . 
A

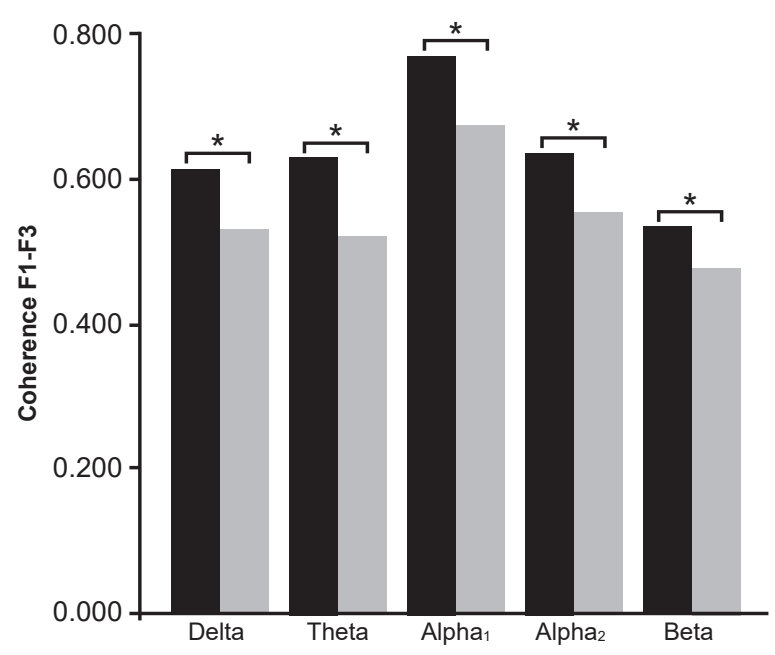

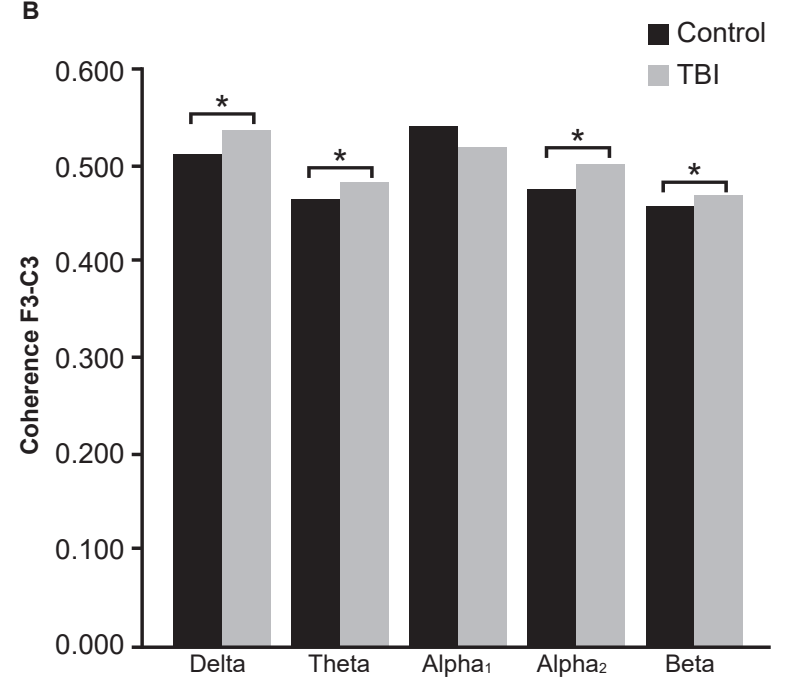

Figure 2. Average values of the spectral coherence on F1-F3 (A) and F3-C3 (B) between the groups $(p \leq .05)$.

and beta frequencies in the TBI group (Figure 2B). Likewise, higher coherence values were observed in the frontal region (F8) at theta and beta frequencies; front-central (C3) at delta, theta, alpha 2 , and beta; temporal (T6) in theta, al$\mathrm{pha}_{1}, \mathrm{alpha}_{2}$, and beta and parietal (P3) in theta, alpha ${ }_{2}$ and beta. It should be noted that the group of children with TBI showed higher coherence values in the beta frequency in practically all the recorded referrals (Figure 1E).

\section{DISCUSSION AND CONCLUSION}

According to the results, the main mechanism of injury in the group of children with TBI was falling. In this type of impact, in addition to a concussive hit, it has been described that the effect of angular acceleration and abrupt deceleration of the head movement can cause a considerable backlash injury and cause tension, section, or tear in the axons of the white matter (Garduño-Hernández, 2008). The neuropsychological outcome in a TBI has been assumed to relate to the degree of axonal injury, as well as the ability of those neural networks to adapt or reconstitute.

Mainly, we observed a deficit in executive processes like graphic fluency and sequential planning and organization, that is, in the ability to select and sequence action plans for the successful resolution of a problem or to generate alternative response strategies (thought or action), depending on the demands of the environment (Anderson, 2002; Monsell, 2003). It is important to emphasize that these were the only items in which the children in the group with chronic TBI showed a performance below what was expected at their age, according to the normative data of the ENI. However, we observed that, with respect to the control group, the sample of children with chronic TBI showed a lower performance in different cognitive domains that are essential for an adequate development and academic performance, one of which was visuospatial processing.

The development and visuospatial functioning includes the perception, analysis, and representation of space through different skills, such as orientation and mental rotation (Banich, 1997). It is possible that after a TBI children may present difficulties to establish spatia 1 relationships involving these skills, as observed in the results. These spatial skills are crucial for the further development of complex systems such as reading (Giovagnoli, Vicari, Tomassetti, \& Menghini, 2016; Vidyasagar \& Pammer, 2010), writing (Carlson, Rowe, \& Curby, 2013; Olive \& Passerault, 2012), and mathematics (Lonnemann, Krinzinger, Knops, \& Willmes, 2008; Wood \& Fischer, 2008), as well as instrumental activities of daily life such as making trips in a city, reading maps and navigation systems (GPS), or understanding manuals to assemble furniture or appliances (Gonzato \& Godino, 2010).

Similarly, we found low performance in attention and memory functions. Specifically, it seems that children with chronic TBI present difficulties in directing attention to those aspects of the environment that are relevant and inhibiting those that are not, which makes them more vulnerable to distraction (Pentland, 1998). In terms of memory, the TBI group showed a lower performance in serial and repetitive learning tasks, as well as in spontaneous and key retrieval, both for verbal and visual memory. Especially, children with TBI showed difficulties in remembering contextualized information from a large volume of information.

However, it should also be noted that, even when significant differences were found in some cognitive domains with respect to the control group, in most of the areas and subtests assessed, the performance of children with chronic TBI was within the average and low average. These findings suggest that children who suffer traumatic brain injury in early childhood may be vulnerable to present a residual 
cognitive decline in later stages of life, as other studies have also pointed out (Anderson, Catroppa, Morse, Haritou, \& Rosenfeld, 2005b; Adamson et al., 2013), or it may be the case that children with chronic TBI may show a delay, but not a disorder, in the development. Nevertheless, children with these difficulties are often found in disadvantage and with a delay in academic learning because they are not able to learn objective information about the world, as most children do (Hood \& Rankin, 2005).

On the other hand, like other studies with fMRI techniques, our results showed significant differences in the functional connectivity both inter and intrahemispherically between the groups (Bonnelle et al., 2011; Caeyenberghs et al., 2012; Han et al., 2016; Hayes et al., 2016; Hillary et al., 2011; Palacios et al., 2013; Rigon, Duff, McAuley, Kramer, \& Voss, 2016; Sharp et al., 2011; Sours, Zhuo, Roys, Shanmuganathan, \& Gullapalli, 2015). The predominant pattern of the sample of children with TBI was a decreased synchronization in the frontal and parietal regions of both hemispheres and in the right temporal region. Among these, the left frontal region stood out with the most marked difference in the five frequency bands with respect to the control group, as other authors have described in adults (von Stein et al., 1999). In particular, it has been pointed out that the lesion of the structures of the front-striatal, front-parietal, and front-temporal tracts generate a significant dysfunction in the functional connectivity present in cases of TBI (Stam $\&$ de Bruin, 2004). Similarly, our findings are consistent with a significant number of studies that have shown an important reduction in connectivity between the structures of the DMN, a neuronal system that involves the parietal-frontal and temporoparietal interhemispheric axonal projection across the spectrum of severity of TBI (Bonelle et al., 2011; Han et al., 2016; Palacios et al., 2013; Stevens et al., 2012; Zhou et al., 2012).

However, in adult patients in a chronic phase, selective increases in functional connectivity have also been found between the central nodes of the DMN (Hayes et al., 2016; Rigon et al., 2016). In the group of children with chronic TBI, an increase in the synchronization of the frontocentral and parietal portion of the left hemisphere was also persistent, as well as of the frontal and temporal portion of the right hemisphere in the different frequency bands. Especially, in more than $80 \%$ of the pairs of electrodes recorded, the functional connectivity in the beta band was found to be considerably increased in the regions closest to the midline in both hemispheres.

Although the functional significance of the oscillatory activity of the EEG in the different frequencies has remained an unknown factor, several studies indicate that long distance communication is mainly based on the synchronization in low frequency bands, while the local communication or at short distances depends on synchronization in the beta and gamma bands (Stam et al., 2012; Thatcher et al., 1986).
Recent work has shown that the transition from slow frequencies to fast frequencies such as the beta rhythm seems to be associated with a mechanism used by the brain to search and establish communication synchronous between specific cerebral regions and spatially separated by several millimeters (von Stein et al., 1999). In particular, it has been observed that the multimodal integration of extensive sensory, associative, and motor areas results from a period of rapid oscillations in the cerebral cortex (Whittington, Faulkner, Doheny, \& Traub, 2000).

Synchronization in the healthy brain is a delicate process characterized by the rapid formation and disappearance of functional connections between the different brain regions (Stam et al., 2012). This dynamic characteristic of synchronization, even during a resting state, can be altered by two principal factors: 1 . Loss of cortical function specialized, and 2. Damage to the connecting paths (Stam et al., 2012; Catani et al., 2005; Smith, Meaney, \& Shull, 2003). Some evidence suggests that abnormalities on white matter in a moderate to severe head injury persist during chronic phase (Kennedy et al., 2009; Nakayama, 2006; Xu, Rasmussen, Lagopoulos, \& Håberg, 2007), and even though there is variability in the tracts that may be damaged, the most vulnerable include long coursing and commissural fibers (Hayes et al., 2016), corpus callosum and fornix (Aoki, Inokuchi, Gunshin, Yahagi, \& Suwa, 2012), internal capsule (Kraus, et al., 2007), and the superior longitudinal fasciculus (Kinnunen et al., 2011). The disruption of these tracts has been associated with important deficiencies in memory, learning, attention, and goal-oriented behavior (Han et al., 2016).

On the other hand, in recent years, new models and techniques that explore the functional connections between different brain areas have shown that TBI is more than a classic disconnection disorder and cortical deficit to also include it as a disorder of hyperconnection and cortical hiperfunction, as demonstrated with other pathologies (Buldú, 2011; Olde Dubbelink et al., 2008; Gorji \& Speckmann, 2009; Jiang, 2005; van Duinkerken et al., 2009).

Our results suggest that it is possible that different networks at rest show alterations in functional connectivity patterns after a TBI, even after several years of injury. If so, the disruption of these neural networks, regardless if the dysfunction is a deficit or excess on transferring information from one area to another, will possibly produce specific cognitive impairments relatable to the specialization system or cortical-subcortical via affected, particularly in the case of children with chronic TBI, with attentional, mnesic, executive, and visuospatial processes.

The occurrence of increased or decreased synchronization (in different frequencies and brain areas) challenges our understanding of the underlying mechanisms and demonstrates the need for a more consistent theoretical framework to study changes in the organization and topological 
properties of neural networks at rest, like the analysis of connectivity based on the theory of graphs (Alducín-Castillo, Yañez-Suárez, \& Brust-Carmona, 2016; Sporns, 2003; Strogatz, 2001).

It is important to note that the differences found in the values of the spectral coherence of chronic TBI children were in the order of hundredths with respect to the control group. It is likely that a subtle difference in the degree of synchronization or connectivity may be determinant in the generation or successful development of some cognitive domains. Neuropsychological evaluation and electrophysiological analysis seem to be tools sensitive to these subtle deficiencies that are otherwise undetectable through general psychometry and standard magnetic resonance (Dockree \& Robertson, 2011).

As we previously indicated, there are a few studies about the typical/atypical maturation of functional connectivity during developmental and almost all use neuroimaging techniques such as fMRI, so the comparison between studies can therefore be challenging and discussion is needed to underscore methodological opportunities and pitfalls in functional connectivity and network studies (van Diessen et al., 2015). To the authors' knowledge, none has evaluated the spectral coherence of EEG in resting state in children with chronic TBI and our results are the first to describe functional connectivity patterns after several years of injury in children. We encourage researchers to explore connectivity measures used in EEG and analyzing a resting state EEG, especially in pediatric studies.

The authors are aware of the number of participants, which make difficult the generalization of the results in the children population. In addition, the limited number of electrodes does not allow us to represent exactly the anatomical and functional topography of the brain. Higher density EEG with 128 or 256 channels can overcome this problem in part, although, inherent to the technique, only superficial aspects of the brain network can be measured. However, the results of this study show that patterns of cortical functional connectivity dysfunction, after TBI at early developmental ages, are complex and may persist for several years after the injury. In addition, the analysis and description of the functional connection in the resting state can be useful in the diagnosis and rehabilitation of neural networks in a TBI, as well as in the development of specific treatments for associated cognitive sequelae.

On the other hand, we consider it necessary to include performance indicators in academic skills that were not assessed in the present study. School performance is part of children's social and personal success; the characterization and timely detection of a delay or alteration in one or more of the processes of speech, language, reading, writing, arithmetic, or other school subjects may favor the psychoeducational intervention necessary in these cases.

Finally, the mechanics derived from the eyes-closed paradigm in wakefulness is a highly replicable and easy to implement version in children, which could be an important biomarker of neurodevelopment that works as a control parameter of the brain's response capacity for pharmacological and non-pharmacological treatments in cases of chronic TBI. However, for future research, we believe that it is necessary to carry out the comparison and correlation analysis with the eyes-open resting condition serving as a convenient activation baseline, especially for task involving visual and cognitive processing.

\section{Conflict of interests}

The authors declare that they have no competing interest.

\section{REFERENCES}

Adamson, C., Yuan, W., Babcock, L., Leach, J. L., Seal, M. L., Holland, S. K., \& Wade, S. L. (2013). Diffusion tensor imaging detects white matter abnormalities and associated cognitive deficits in chronic adolescent TBI. Brain Injury, 27(4), 454-463. doi: 10.3109/02699052.2012.750756

Adelson, P. D., Bratton, S. L., Carney, N. A., Chesnut, R. M., Du Coudray, H. E., Goldstein, B., ... \& Wright, D. W. (2003). Guidelines for the acute medical management of severe traumatic brain injury in infants, children, and adolescents. Chapter I: Introduction. Pediatric Critical Care Medicine: a journal of the Society of Critical Care Medicine and the World Federation of Pediatric Intensive and Critical Care Societies, 4(3 Supp1), S2-4. doi: 10.1097/01.CCM.0000066600.71233.01

Alducín-Castillo, J., Yañez-Suárez, O., \& Brust-Carmona, H. (2016). Análisis electroencefalográfico de la conectividad funcional en habituación por teoría de gráficas. Revista Mexicana de Ingeniería Biomédica, 37(3), 181-200. doi: 10.17488/rmib.37.3.3

Alhaddad, M. J. (2012). Common Average Reference (CAR) improves p300 speller. International Journal of Engineering and Technology, 2(3), 21. Recuperado de: https://www.researchgate.net/publication/265881476_Common_Average_ Reference_CAR_Improves_P300_Speller

AMAI (2013). Cuestionario regla AMAI NSE 8x7. Recuperado de: http://www.amai. org/NSE/CUESTIONARIO-REGLA-AMAI-NSE-8X7_20110907.pdf

Anderson, P. (2002). Assessment and development of executive function (EF) during childhood. Child Neuropsychology, 8(2), 71-82. doi: 10.1076/chin.8.2.71.8724

Anderson, V. \& Catroppa, C. (2005). Recovery of executive skills following pediatric traumatic brain injury (TBI): A 2 year follow-up. Brain Injury, 19(6), 459-470. doi: 10.1080/02699050400004823

Anderson, V., Catroppa, C., Morse, S., Haritou, F., \& Rosenfeld, J. (2005a). Attentional and processing skills following traumatic brain injury in early childhood. Brain Injury, 19(9), 699-710. doi: 10.1080/02699050400025281

Anderson, V., Catroppa, C., Morse, S., Haritou, F., \& Rosenfeld, J. (2005b). Functional plasticity or vulnerability after early brain injury? Pediatrics, 116(6), 1374-1382. doi: 10.1542/peds.2004-1728

Aoki, Y., Inokuchi, R., Gunshin, M., Yahagi, N., \& Suwa, H. (2012). Diffusion tensor imaging studies of mild traumatic brain injury: A meta-analysis. Journal of Neurology, Neurosurgery, \& Psychiatry, 83(9), 870-876. doi: 10.1136/ jnnp.2012-302742

Banich M. T. (1997). Spatial Processing. In: M. T. Banich (Ed), Neuropsychology: The Neural Bases of Mental function (pp. 202-233). Boston MA: Houghton Mifflin Company.

Barry, R. J., Clarke, A. R., McCarthy, R., Selikowitz, M., Johnstone, S. J., \& Rushby, J. A. (2004). Age and gender effects in EEG coherence: I. Developmental trends in normal children. Clinical Neurophysiology, 115(10), 2252-2258. doi: 10.1016/j.clinph.2004.05.004

Bathelt, J., O'reilly, H., Clayden, J. D., Cross, J. H., \& de Haan, M. (2013). Functional brain network organization of children between 2 and 5 years derived from reconstructed activity of cortical sources of high-density EEG recordings. NeuroImage, 82, 595-604. doi: 10.1016/j.neuroimage.2013.06.003 
Bell, M. A. \& Cuevas, K. (2012). Using EEG to study cognitive development: Issues and practices. Journal of Cognition and Development, 13(3), 281-294. doi: 10.1080/15248372.2012.691143

Blennow, K., Hardy, J., \& Zetterberg, H. (2012). The neuropathology and neurobiology of traumatic brain injury. Neuron, 76(5), 886-899. doi: 10.1016/j. neuron.2012.11.021

Bonnelle, V., Leech, R., Kinnunen, K. M., Ham, T. E., Beckmann, C. F., De Boissezon, X., ... \& Sharp, D. J. (2011). Default mode network connectivity predicts sustained attention deficits after traumatic brain injury. Journal of Neuroscience, 31(38), 13442-13451. doi: 10.1523/ JNEUROSCI.1163-11.2011

Buldú, J. M., Bajo, R., Maestú, F., Castellanos, N., Leyva, I., Gil, P., ... \& Boccaletti, S. (2011). Reorganization of functional networks in mild cognitive impairment. PloS One, 6(5), e19584. doi: 10.1371/journal.pone.0019584

Caeyenberghs, K., Leemans, A., Heitger, M. H., Leunissen, I., Dhollander, T., Sunaert, S., ... \& Swinnen, S. P. (2012). Graph analysis of functional brain networks for cognitive control of action in traumatic brain injury. Brain, 135(4), 1293-1307. doi: 10.1093/brain/aws048

Carlson, A. G., Rowe, E., \& Curby, T. W. (2013). Disentangling fine motor skills' relations to academic achievement: the relative contributions of visual-spatial integration and visual- motor coordination. The Journal of Genetic Psychology, 174(5), 514-533. doi: 10.1080/00221325.2012.717122

Catani, M. \& Ffytche, D. H. (2005). The rises and falls of disconnection syndromes. Brain, 128(10), 2224-2239. doi: 10.1093/brain/awh622

Corsi-Cabrera, M., Galindo-Vilchis, L., del-Río-Portilla, Y., Arce, C., \& RamosLoyo, J. (2007). Within-subject reliability and inter-session stability of EEG power and coherent activity in women evaluated monthly over nine months. Clinical Neurophysiology, 118(1), 9-21. doi: 10.1016/j.clinph.2006.08.013

Dockree, P. M. \& Robertson, I. H. (2011). Electrophysiological markers of cognitive deficits in traumatic brain injury: a review. International Journal of Psychophysiology, 82(1), 53-60. doi: 10.1016/j.ijpsycho.2011.01.004

Ewing-Cobbs, L. \& Barnes, M. (2002). Linguistic outcomes following traumatic brain injury in children. Seminars in Pediatric Neurology, 9(3), 209-217. doi: 10.1053/spen.2002.35502

Ewing-Cobbs, L., Barnes, M., Fletcher, J. M., Levin, H. S., Swank, P. R., \& Song, J. (2004). Modeling of longitudinal academic achievement scores after pediatric traumatic brain injury. Developmental Neuropsychology, 25(1-2), 107-133. doi: 10.1080/87565641.2004.9651924

Garduño-Hernández, F. (2008). Traumatismo craneoencefálico en niños: Mecanismos de la lesión primaria. Boletín Médico del Hospital Infantil de México, 65(2), 148-153.

Giovagnoli, G., Vicari, S., Tomassetti, S., \& Menghini, D. (2016). The Role of VisualSpatial Abilities in Dyslexia: Age Differences in Children's Reading? Frontiers in Psychology, 7, 1997. doi: 10.3389/fpsyg.2016.01997

Gmehlin, D., Thomas, C., Weisbrod, M., Walther, S., Resch, F., \& Oelkers-Ax, R. (2011). Development of brain synchronisation within school-age-Individual analysis of resting (alpha) coherence in a longitudinal data set. Clinical Neurophysiology, 122(10), 1973-1983. doi: 10.1016/j.clinph.2011.03.016

Gonzato, M. \& Godino, J. D. (2010). Aspectos históricos, sociales y educativos de la orientación espacial. Revista Iberoamericana de Educación Matemática, $23,45-58$.

Gorji, A. \& Speckmann, E. J. (2009). Epileptiform EEG spikes and their functional significance. Clinical EEG and Neuroscience, 40(4), 230-233. doi: 10.1177/155005940904000404

Han, K., Chapman, S. B., \& Krawczyk, D. C. (2016). Disrupted intrinsic connectivity among default, dorsal attention, and frontoparietal control networks in individuals with chronic traumatic brain injury. Journal of the International Neuropsychological Society, 22(2), 263- 279. doi: 10.1017/ S1355617715001393

Hannawi, Y. \& Stevens, R. D. (2016). Mapping the Connectome following traumatic brain Injury. Current Neurology and Neuroscience Reports, 16(5), 44. doi: 10.1007/s11910-016-0642-9

Hayes, J. P., Bigler, E. D., \& Verfaellie, M. (2016). Traumatic brain injury as a disorder of brain connectivity. Journal of the International Neuropsychological Society, 22(2), 120-137. doi: 10.1017/S1355617715000740
Hillary, F. G., Slocomb, J., Hills, E. C., Fitzpatrick, N. M., Medaglia, J. D., Wang, J., ... \& Wylie, G. R. (2011). Changes in resting connectivity during recovery from severe traumatic brain injury. International Journal of Psychophysiology, 82(1), 115-123. doi: 10.1016/j.ijpsycho.2011.03.011

Hood, J. \& Rankin, P. M. (2005). How do specific memory disorders present in the school classroom? Pediatric Rehabilitation, 8(4), 272-282. doi: $10.1080 / 13638490400022303$

Instituto Nacional de Estadística y Geografía (INEGI). Consultado 09-02-2015 en http:/www.inegi.org.mx/sistemas/TabuladosBasicos/Default

Jiang, Z. Y. (2005). Study on EEG power and coherence in patients with mild cognitive impairment during working memory task. Journal of Zhejiang University Science B, 6(12), 1213-1219. doi: 10.1631/jzus.2005.B1213

Kennedy, M. R. T., Wozniak, J. R., Muetzel, R. L., Mueller, B. A., Chiou, H. H., Pantekoek, K., \& Lim, K. O. (2009). White matter and neurocognitive changes in adults with chronic traumatic brain injury. Journal of the International Neuropsychological Society, 15(1), 130-136. doi: 10.1017/S1355617708090024

Khundrakpam, B. S., Lewis, J. D., Zhao, L., Chouinard-Decorte, F., \& Evans, A. C. (2016). Brain connectivity in normally developing children and adolescents. Neuroimage, 134, 192-203. doi: 10.1016/j.neuroimage.2016.03.062

Kinnunen, K. M., Greenwood, R., Powell, J. H., Leech, R., Hawkins, P. C., Bonnelle, V., ... \& Sharp, D. J. (2011). White matter damage and cognitive impairment after traumatic brain injury. Brain, 134(2), 449-463. doi:

Kirkwood, M. W., Yeates, K. O., Taylor, H. G., Randolph, C., McCrea, M., \& Anderson, V. A. (2008). Management of pediatric mild traumatic brain injury: A neuropsychological review from injury through recovery. The Clinical Neuropsychologist, 22(5), 769-800. doi: 10.1080/13854040701543700

Kraus, M. F., Susmaras, T., Caughlin, B. P., Walker, C. J., Sweeney, J. A., \& Little, D. M. (2007). White matter integrity and cognition in chronic traumatic brain injury: a diffusion tensor imaging study. Brain, 130(10), 2508-2519. doi: 10.1093/brain/awm216

Levin, H. S. \& Hanten, G. (2005). Executive functions after traumatic brain injury in children. Pediatric Neurology, 33(2), 79-93. doi: 10.1016/j. pediatrneurol.2005.02.002

Lonnemann, J., Krinzinger, H., Knops, A., \& Willmes, K. (2008). Spatial representations of numbers in children and their connection with calculation abilities. Cortex, 44(4), 420-428. doi: 10.1016/j.cortex.2007.08.015

Matute, E., Rosselli, M., Ardila, A., \& Ostrosky-Solís, F. (2007). ENI: Evaluación Neuropsicológica Infantil. Guadalajara, México: Manual Moderno/Universidad de Guadalajara.

Monsell, S. (2003). Task switching. Trends in Cognitive Sciences, 7(3), 134-140. doi: 10.1016/S1364-6613(03)00028-7

Murias, M., Swanson, J. M., \& Srinivasan, R. (2007). Functional connectivity of frontal cortex in healthy and ADHD children reflected in EEG coherence. Cerebral Cortex, 17(8), 1788- 1799. doi: 10.1093/cercor/bh1089

Muscara, F., Catroppa, C., \& Anderson, V. (2008). The impact of injury severity on executive function 7-10 years following pediatric traumatic brain injury. Developmental Neuropsychology, 33(5), 623-636. doi: $10.1080 / 87565640802171162$

Nadebaum, C., Anderson, V., \& Catroppa, C. (2007). Executive function outcomes following traumatic brain injury in young children: a five year follow-up. Developmental Neuropsychology, 32(2), 703-728. doi: 10.1080/87565640701376086

Nakayama, N., Okumura, A., Shinoda, J., Yasokawa, Y. T., Miwa, K., Yoshimura, S. I., \& Iwama, T. (2006). Evidence for white matter disruption in traumatic brain injury without macroscopic lesions. Journal of Neurology, Neurosurgery \& Psychiatry, 77(7), 850-855. doi: 10.1136/jnnp.2005.077875

Nunez, P. L., Srinivasan, R., Westdorp, A. F., Wijesinghe, R. S., Tucker, D. M., Silberstein, R. B., \& Cadusch, P. J. (1997). EEG coherency: I: statistics, reference electrode, volume conduction, Laplacians, cortical imaging, and interpretation at multiple scales. Electroencephalography and Clinical Neurophysiology, 103(5), 499-515. doi: 10.1016/S0013-4694(97)00066-7

Olde Dubbelink, K. T. E., Felius, A., Verbunt, J. P. A., Van Dijk, B. W., Berendse, H. W., Stam, C. J., \& Delemarre-van de Waal, H. A. (2008). Increased resting-state functional connectivity in obese adolescents; a magnetoencephalographic pilot study. PLoS One, 3(7), e2827. doi: 10.1371/journal.pone.0002827 
Olive, T. \& Passerault, J. M. (2012). The visuospatial dimension of writing. Written Communication, 29(3), 326-344. doi: 10.1177/0741088312451111

Palacios, E. M., Sala-Llonch, R., Junque, C., Roig, T., Tormos, J. M., Bargallo, N., \& Vendrell, P. (2013). Resting-state functional magnetic resonance imaging activity and connectivity and cognitive outcome in traumatic brain injury. JAMA Neurology, 70(7), 845-851. doi: 10.1001/jamaneurol.2013.38

Pan, S. Y., Ugnat, A. M., Semenciw, R., Desmeules, M., Mao, Y., \& Macleod, M. (2006). Trends in childhood injury mortality in Canada, 1979-2002. Injury Prevention, 12(3), 155-160. doi: 10.1136/ip.2005.010561

Paus, T. (2007). Maturation of structural and functional connectivity in the human brain. In: V. K. Jirsa, A. McIntosh (Eds), Handbook of Brain Connectivity, Understanding Complex Systems (pp. 463-475). Springer, Berlin, Heidelberg. 10.1007/978-3-540-71512-2_16

Pentland, V. A. L. (1998). Residual attention deficits following childhood head injury: Implications for ongoing development. Neuropsychological Rehabilitation, 8(3), 283-300. doi: 10.1080/713755569

Ramlackhansingh, A. F., Brooks, D. J., Greenwood, R. J., Bose, S. K., Turkheimer, F. E., Kinnunen, K. M., ... \& Sharp, D. J. (2011). Inflammation after trauma: microglial activation and traumatic brain injury. Annals of Neurology, 70(3), 374-383. doi: 10.1002/ana.22455

Rigon, A., Duff, M. C., McAuley, E., Kramer, A. F., \& Voss, M. W. (2016). Is traumatic brain injury associated with reduced inter-hemispheric functional connectivity? A study of large-scale resting state networks following traumatic brain injury. Journal of Neurotrauma, 33(11), 977-989. doi: 10.1089/neu.2014.3847

Sakkalis, V. (2011). Review of advanced techniques for the estimation of brain connectivity measured with EEG/MEG. Computers in Biology and Medicine, 4l(12), 1110-1117. doi: 10.1016/j.compbiomed.2011.06.020

Sharp, D. J., Beckmann, C. F., Greenwood, R., Kinnunen, K. M., Bonnelle, V., De Boissezon, X., ... \& Leech, R. (2011). Default mode network functional and structural connectivity after traumatic brain injury. Brain, 134(8), 2233-2247. doi: 10.1093/brain/awr175

Smith, D. H., Meaney, D. F., \& Shull, W. H. (2003). Diffuse axonal injury in head trauma. The Journal of Head Trauma Rehabilitation, 18(4), 307-316. PMID: 16222127

Sours, C., Zhuo, J., Roys, S., Shanmuganathan, K., \& Gullapalli, R. P. (2015). Disruptions in resting state functional connectivity and cerebral blood flow in mild traumatic brain injury patients. PloS One, 10(8), e0134019. doi: 10.1371/ journal.pone.0134019

Sporns, O. (2003). Graph theory methods for the analysis of neural connectivity patterns. In: R. Kötter (Ed.), Neuroscience databases (pp. 171-185). Boston, MA: Springer. doi: 10.1007/978-1-4615-1079-6_12

Stam, C. J. \& de Bruin, E. A. (2004). Scale-free dynamics of global functional connectivity in the human brain. Human Brain Mapping, 22(2), 97-109. doi: $10.1002 / \mathrm{hbm} .20016$

Stam, C. J. \& van Straaten, E. C. W. (2012). The organization of physiological brain networks. Clinical Neurophysiology, 123(6), 1067-1087. doi: 10.1016/j. clinph.2012.01.011

Stevens, M. C., Lovejoy, D., Kim, J., Oakes, H., Kureshi, I., \& Witt, S. (2012). Multiple resting state network functional connectivity abnormalities in mild traumatic brain injury. Brain Imaging and Behavior, 6(2), 293-318. doi: 10.1007/s11682-012-9157-4

Stocchetti, N., Conte, V., Ghisoni, L., Canavesi, K., \& Zanaboni, C. (2010). Traumatic brain injury in pediatric patients. Minerva Anestesiologica, 76(12), 1052-1059. PMID:21178914

Strogatz, S. H. (2001). Exploring complex networks. Nature, 410(6825), 268-276. doi: $10.1038 / 35065725$
Taylor, H. G. \& Alden, J. (1997). Age-related differences in outcomes following childhood brain insults: an introduction and overview. Journal of the International Neuropsychological Society, 3(6), 555-567.

Taylor, H. G., Yeates, K. O., Wade, S. L., Drotar, D., Stancin, T., \& Minich, N. (2002). A prospective study of short-and long-term outcomes after traumatic brain injury in children: behavior and achievement. Neuropsychology, 16(1), 15-27. doi: $10.1037 / 0894-4105.16 .1 .15$

Thatcher, R. W., Krause, P. J., \& Hrybyk, M. (1986). Cortico-cortical associations and EEG coherence: a two-compartmental model. Electroencephalography and Clinical Neurophysiology, 64(2), 123-143. doi: 10.1016/0013-4694(86)90107-0

Thatcher, R. W., North, D. M., \& Biver, C. J. (2008). Development of cortical connections as measured by EEG coherence and phase delays. Human Brain Mapping, 29(12), 1400-1415. doi: 10.1002/hbm.20474

van Diessen, E., Numan, T., van Dellen, E., van der Kooi, A. W., Boersma, M., Hofman, D., ... \& Stam, C. J. (2015). Opportunities and methodological challenges in EEG and MEG resting state functional brain network research. Clinical Neurophysiology, 126(8), 1468-1481. doi: 10.1016/j.clinph.2014.11.018

van Duinkerken, E., Klein, M., Schoonenboom, N. S., Hoogma, R. P., Moll, A. C., Snoek, F. J., ... \& Diamant, M. (2009). Functional Brain Connectivity and Neurocognitive Functioning in Patients with Long-standing Type 1 Diabetes with and without Microvascular Complications: a Magnetoencephalography Study. Diabetes, 58(10), 2335-2343. doi: 10.2337/db09-0425

Vidyasagar, T. R. \& Pammer, K. (2010). Dyslexia: a deficit in visuo-spatial attention, not in phonological processing. Trends in Cognitive Sciences, 14(2), 57-63. doi: 10.1016/j.tics.2009.12.003

von Stein, A. \& Sarnthein, J. (2000). Different frequencies for different scales of cortical integration: from local gamma to long range alpha/theta synchronization. International Journal of Psychophysiology, 38(3), 301-313. doi: 10.1016/ S0167- 8760(00)00172-0

von Stein, A., Rappelsberger, P., Sarnthein, J., \& Petsche, H. (1999). Synchronization between temporal and parietal cortex during multimodal object processing in man. Cerebral Cortex, 9(2), 137-150. doi: 10.1093/cercor/9.2.137

Welch, P. (1967). The use of fast Fourier transform for the estimation of power spectra: a method based on time averaging over short, modified periodograms. IEEE Transactions on Audio and Electroacoustics, 15(2), 70-73. doi: 10.1109/ TAU.1967.1161901

Whittington, M. A., Faulkner, H. J., Doheny, H. C., \& Traub, R. D. (2000). Neuronal fast oscillations as a target site for psychoactive drugs. Pharmacology \& Therapeutics, 86(2), 171-190. doi: 10.1016/S0163-7258(00)00038-3

Wood, G. \& Fischer, M. H. (2008). Numbers, space, and action-from finger counting to the mental number line and beyond. Cortex, 44(4), 353-358. doi: 10.1016/j. cortex.2008.01.002

Xu, J., Rasmussen, I. A., Lagopoulos, J., \& Håberg, A. (2007). Diffuse axonal injury in severe traumatic brain injury visualized using high-resolution diffusion tensor imaging. Journal of Neurotrauma, 24(5), 753-765. doi: 10.1089/neu.2006.0208

Yeates, K. O., Blumenstein, E., Patterson, C. M., \& Delis, D. C. (1995). Verbal learning and memory following pediatric closed-head injury. Journal of the International Neuropsychological Society, 1(1), 78-87. doi: 10.1017/S1355617700000138

Yeo, B. T., Krienen, F. M., Sepulcre, J., Sabuncu, M. R., Lashkari, D., Hollinshead, M., ... \& Buckner, R. L. (2011). The organization of the human cerebral cortex estimated by intrinsic functional connectivity. Journal of Neurophysiology, 106(3), 1125-1165. doi: 10.1152/jn.00338.2011

Zhou, Y., Milham, M. P., Lui, Y. W., Miles, L., Reaume, J., Sodickson, D. K., ... \& Ge, Y. (2012). Default-mode network disruption in mild traumatic brain injury. Radiology, 265(3), 882- 892. doi: 10.1148/radiol.12120748 